International Journal of Instruction e-ISSN: 1308-1470 • www.e-iji.net

Article submission code: 20200302003246

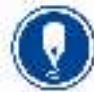

Received: 02/03/2020 Revision: 07/10/2020
April 2021 • Vol.14, No.2

p-ISSN: 1694-609X

pp. 591-608

Accepted: 28/10/2020

OnlineFirst: 14/02/2021

\title{
The Statistical Creative Framework in Descriptive Statistics Activities
}

\author{
Subanji \\ Assoc. Prof., Mathematics Department, Faculty of Mathematics and Science, \\ Universitas Negeri Malang, Indonesia, subanji.fmipa@um.ac.id

\section{Toto Nusantara} \\ Prof., Mathematics Department, Faculty of Mathematics and Science, Universitas \\ Negeri Malang, Indonesia, toto.nusantara.fmipa@um.ac.id

\section{Desi Rahmatina} \\ Asst. Prof., Mathematics Education Department, Universitas Maritim Raja Ali Haji, \\ Tanjungpinang, Indonesia, desirahmatina@umrah.ac.id

\section{Heri Purnomo} \\ Ph.D Candidate Mathematics Department, Faculty of Mathematics and Science, \\ Universitas Negeri Malang, Indonesia, heri.purnomo.1803119@students.um.ac.id
}

This research aimed to construct a statistical creative model in solving the problem of descriptive statistics. This type of research is a mixed methods research with a sequential mixed methods model using Exploratory sequential design. A descriptive qualitative method is used to build statistical creative models. Meanwhile, a quantitative method is used to test whether there are significant differences in students' statistical creative models based on gender. The research was conducted on 124 high school students with a distribution of 59 boys and 65 girls (15-18 years of age). The results of this research found that there are three levels of a statistical creative model in descriptive statistical activities, namely imitation, modification, and construction. A total of 25 subjects were at the imitation level, in solving problems the subjects imitated the appearance of data, graphics, or resolution strategies. 56 subjects at the modification level, modified the data or graphic display to solve the problem. 43 subjects at the construction level are shown by constructing new data or graphics to solve the problem. It was also found that there were no significant differences in the creative models of male and female subjects in descriptive statistical activities.

Keywords: creative model, descriptive statistics, line graph, bar chart, statistics

\section{INTRODUCTION}

Creative thinking is an important component in learning Mathematics. Some researchers examine students' creative thinking through components of fluency, flexibility and

Citation: Subanji., Nusantara, T., Rahmatina, D., \& Purnomo, H. (2021). The Statistical Creative Framework in Descriptive Statistics Activities. International Journal of Instruction, 14(2), 591-608. https://doi.org/10.29333/iji.2021.14233a 
originality in solving open problems (Kattou \& Kontoyianni, 2012; Tabach \& Friedlander, 2013). Fluency is evaluated referring to the number of different methods for solving a given problem. Flexibility is associated with the ability to change ideas to produce various methods of resolution. Originality refers to the emergence of new ideas related to how to solve problems. Furthermore, Kattou \& Kontoyianni (2012) investigated the structure of the relationship between mathematical ability and creativity. From the results of the research, it was found that there were three categories of students that differ according to their mathematical abilities, namely: students with low, medium, and high mathematical abilities. Meanwhile, the mathematical creativity of the three categories also varied so that it was found that students with the highest scores on the Mathematics test were also the most creative. Sriraman \& Hadamard (2009) conducted a study of five Mathematicians to determine the characteristics of the creative process, the results of the research showed that the creative process of Mathematicians followed the four stages of the Gestalt model namely preparation-incubation-illuminationverification. In this case, the creative process can occur in the process of learning mathematical material, including statistics.

The National Council of Teachers of Mathematics (2007) includes statistics on data analysis and probability in the Mathematics curriculum from elementary school to high school. This shows the role of statistics as an important part in Mathematics. Likewise in the Mathematics curriculum in Indonesia, statistical material is also contained from the level of elementary school to higher education. This is because the role of statistics is very broad in various fields such as education, health, agriculture, economics, and law. Statistics is the science of collecting data, analyzing, presenting, and interpreting and making decisions (Mann, 2013). Statistics is divided into two namely descriptive statistics and inferential statistics (Creswell, 2012). The scope of descriptive statistics is central tendency measures and dispersion measures, while inferential statistics include hypothesis testing which can generalize samples to make conclusions about population characteristics. In this research, the resercher applied descriptive statistics in presenting data in the form of line graphs and bar charts. The types of graphs are determined by qualitative or quantitative data types (Cooper \& Shore, 2010). For example, bar charts and pie charts are used to represent qualitative data distribution (nominal or ordinal scale), while histograms, line graphs, leaf bar charts are used for quantitative data (interval or ratio scale). In this case, the ability to read graphs or charts is an important component that students must have in understanding information.

Sharma (2006) presents and discusses methods applied by students in understand information from graphic representations in the form of tables and bar charts. The results of his research show that many students used strategies based on previous experiences and used intuitive strategies. Furthermore, Aoyama (2007) investigated the hierarchy of students' interpretations of graphs showing that there were some obstacles for junior students to think about open questions caused by their limited learning experiences. Mann (2013) explains that descriptive statistics contain ways of collecting data, displaying and describing data using tables, graphs and summaries of central tendency. Representation of data in the form of graphs is mostly found in print and electronic media, so a further understanding of the use of graphics to interpret scores is 
needed. Students' activity in descriptive statistics studied in this research is in the form of data presentation in the form of line graphs and bar charts in solving central tendency measures problems. The problem used in this research was an open problem, so it requires creative thinking in solving it.

Creative thinking is needed in solving problems in everyday life. Creative thinking can be developed through mathematical activities (Sriraman, 2009; Brunkalla, 2009; Nadjafikhah, Yaftian, \& Bakhshalizadeh, 2012; Baran, Erdogan, \& Cakmak, 2011; Voica \& Singer, 2012; Svecova, Rumanova, \& Pavlovicova, 2014; Sharma, 2014). This is based on the idea that Mathematics is related to ideas, structures, and relationships that are constructed using logic. Truth in Mathematics is developed based on logical and systematic arguments. Mathematical activities are mostly based on logical and systematic thinking processes including making and testing hypotheses, looking for analogies, making connections, making representations, making generalizations, proving theorems, and ultimately solving problems. In carrying out these mathematical activities, it requires high-level thinking that requires students to think critically and creatively.

Creative thinking that occurs in mathematical activities is called mathematical creative thinking and is often associated with problem solving (NCTM, 2000; Chamberlin \& Moon, 2005; Baran, Erdogan, \& Cakmak, 2011; Sriraman, Haavold \& Lee, 2013). NCTM (2000) proposes that students be given challenging problems that can foster their mathematical creative thinking. This can occur because problem solving enables students to hone creative thinking skills through various solutions. Baran, Erdogan \& Cakmak (2011) have found that mathematical creativity can be seen from the ability to solve problems, especially in open mathematical situations. Chamberlin \& Moon (2005) have found creativity in mathematical thinking processes related to non-routine problem solving. This means that problem solving is one of the aspects of mathematical creative thinking. Furthermore, Beghetto (2017) argues that routine training must be balanced in new and creative ways. The balance can be achieved by the teacher by turning some routine tasks into non-routine problems.

Several researchers have reviewed mathematical creative thinking (Lin \& Cho, 2011; Baran, Erdogan, \& Cakmak, 2011; Voica \& Singer, 2012; Coxbill, Chamberlin \& Weatherford, 2013). Lin \& Cho (2011) developed a model of creative problem solving ability to predict students' creativity in solving mathematical problems. Baran, Erdogan, \& Cakmak (2011) have found a relationship between creativity and mathematical ability based on gender. Voica \& Singer (2012) examined the creativity of students who are gifted in Mathematics found that students who master Mathematics thoroughly have good creativity. Coxbill, Chamberlin \& Weatherford (2013) developed and traced students' mathematical creativity using Model-Eliciting-Activities (MEASs). The importance of growing and developing student creativity in learning Mathematics has been reviewed by Sheffield $(2009,2013)$. The development of students' creativity can be done through understanding Mathematics (Leikin \& Pitta-Pantazi, 2013; Schindler \& Lilienthal, 2019). From some of these studies show the importance of assessing students' mathematical creativity. 
This research aimed to construct mathematical creative models in descriptive statistical activities and explore whether there are differences in creative models in terms of gender. Descriptive statistics used in this research are related to the presentation of data in the form of line graphs and central tendency (mean, median and modus) presented in the form of bar charts. Creative models were constructed from creative frameworks on general problems and adapted to mathematical characteristics, especially statistics, hereinafter referred to as mathematical creative models.

\section{A Framework of Mathematical Creative Model}

Mathematical creative thinking is part of general creativity. Creativity can be considered as a mental process involving new ideas or concepts (Leikin \& Lev, 2013; Yaftian, 2015). Mathematical creativity is a form of creativity that has a special object of study namely Mathematics. Therefore, the development of a mathematical creative framework is based on a general creative framework taking into account the characteristics of mathematical structures. In the context of general creativity that occurs in everyday life, creativity can be grouped in three levels of creative models: (1) imitation, (2) modification, and (3) construction. The lowest level is to imitate, hereinafter referred to as the imitation model, occurs when someone wants to make a product by imitating existing products. The second level is to modify, hereinafter referred to as the modification model, which occurs when someone examines the "function/benefit/form" of a product and converts it into a new product. The highest level is to construct, hereinafter referred to as the creation model, which occurs when someone makes a new product without seeing the related product that already exists. The main consideration is that there are problems in daily life that need to be solved through a product.

From general creative models, it can be developed in a mathematical context, hereinafter referred to as mathematical creative models. In accordance with general creativity, mathematical creative models are grouped into 3 (three) levels: imitation, modification, and construction. The framework for developing mathematical creative models based on general creativity is presented in Table 1 below.

Table 1

Creative model frame work

\begin{tabular}{lll}
\hline Creative Model & General Creativity & Mathematical Creativity \\
\hline Imitation & $\begin{array}{l}\text { Imitating a product with a simpler } \\
\text { process or lower cost. }\end{array}$ & $\begin{array}{l}\text { Just imitating a similar form of } \\
\text { resolution to solve the problem at hand. }\end{array}$ \\
\hline Modification & $\begin{array}{l}\text { Changing the function/benefit/ } \\
\text { form of a product so that it } \\
\text { becomes a new product. }\end{array}$ & $\begin{array}{l}\text { Changing the problem/data/ resolution } \\
\text { procedure so that it gets a more efficient } \\
\text { solution. }\end{array}$ \\
\hline Construction & $\begin{array}{l}\text { Creating a new work that is more } \\
\text { interesting, more practical, and has } \\
\text { more functions. }\end{array}$ & $\begin{array}{l}\text { Constructing a new resolution } \\
\text { procedure in accordance with the } \\
\text { demands of the problem. }\end{array}$ \\
\hline
\end{tabular}

In this research, the task given relates to the specific mathematical problem of descriptive statistics material, so that the creative model studied is called a statistical 
creative model. The statistical creative model framework for completing descriptive statistical tasks is presented in Table 2.

Table 2

A framework of statistical creative models

\begin{tabular}{ll}
\hline Creative Model & Statistical Creative Model Indicators \\
\hline Imitation & $\begin{array}{l}\text { Imitating the score or form of data display or collection of data to solve the } \\
\text { problem at hand. }\end{array}$ \\
& $\begin{array}{l}\text { Imitating the existing chart or data on the problem. } \\
\text { Imitating the resolution strategy that has been used. }\end{array}$ \\
\hline Modification & $\begin{array}{l}\text { Modifying some scores or forms of data display/data set to solve the problem. } \\
\text { Modifying the resolution strategy to solve the problem. }\end{array}$ \\
\hline Construction & $\begin{array}{l}\text { Constructing a data display or set of data so that new data display is obtained } \\
\text { whose scores or forms are different from the existing data displays according } \\
\text { to problem demands. } \\
\text { Arranging new strategies to solve problems. }\end{array}$ \\
\hline
\end{tabular}

\section{METHOD}

This research method used a Sequential mixed methods model with Exploratory sequential design, beginning with a qualitative design and continuing with quantitative. A descriptive qualitative method was used to explore statistical creative models in activities to solve descriptive statistical problems. Meanwhile, a quantitative method was used to test whether there are differences in creative models between male and female subjects by Chi-square test. This research was conducted at two high schools in two different Provinces in Indonesia, namely SMAN 3 Malang, East Java Province and SMAN 2 Tanjungpinang, Riau Islands Province. 59 males and 65 females out of 137 students ranging from 15-18 years of age became respondents in this research. There were 13 out of 137 students whose answers were inconsistent or only answered one assignment out of the two assignments, so they were not analyzed further.

The instruments in this research were written tests of two tasks and interview guidelines. The instruments are equipped with rubric and validated by two mathematics education experts. The two assignments were made for triangulation in order to obtain consistent data related to the level of mathematical creative models. After students completed the assignment, the researcher grouped students' answers based on creative models and conducted semi structured interviews to confirm students' creative models. Voice recordings using mobile phones during interviews were made so that no information by students was missed. The tasks given to the research subjects are as follows.

\section{TASK 1}

A shop sells two soft drinks "Teh Botol" and "Teh Kotak" from 2000 to 2009. The chart below shows the results of the sale of "Teh Botol" drinks for 5 years. Make a line graph of the sales of "Teh Botol" and "Teh Kotak" in one graph so that in 2009 the sales of the two soft drinks are equal.

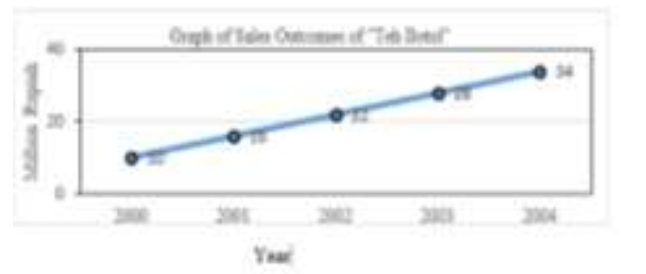




\section{TASK 2}

A Math teacher teaches in two classes, namely class A and class B. Table 1 below is the result of Math class A scores. There are 35 people in class B. Make a bar chart of Math class B scores (Scores 0 - 100) if the mean, median, and mode class B scores are greater than class $\mathrm{A}$.

Figure 1

The descriptive statistics task

\section{FINDINGS}

The 124 subjects who answered consistently were distributed based on the level of the creative model: 25 subjects $(20.16 \%)$ were at the imitation level marked by the process of solving problems by imitating the appearance of data, graphics, or resolution strategies; 56 subjects $(45.16 \%)$ at the modification level, which was marked by the process of modifying the display of data or graphics to solve the problems; and 43 subjects $(34.68 \%)$ at the construction level marked by the process of solving problems by constructing new data or graphics. It appears that most subjects are at the modification level of creative model. Furthermore, if traced by gender, the distribution of creative models can be displayed in Table 3 .

Table 3

Gender-based creative model distribution

\begin{tabular}{lllll}
\hline \multirow{2}{*}{ Gender } & \multicolumn{2}{l}{ Creative Model Level } & \multirow{2}{*}{ Total } \\
\cline { 2 - 4 } & Imitation & Modification & Construction & \\
\hline Male & $12(9.7 \%)$ & $26(21.0 \%)$ & $21(16.9 \%)$ & $59(47.6 \%)$ \\
\hline Female & $13(10.5 \%)$ & $30(24.2 \%)$ & $22(17.7 \%)$ & $65(52.4 \%)$ \\
\hline
\end{tabular}

In carrying out descriptive statistical activities, most male and female students are at the modification level of creative model. The following is the subject's creative model in completing descriptive statistical tasks for each level.

\section{The Imitation Level of Statistical Creative Model}

The imitation level of creative model is characterized by activities that imitate the context or problem solving strategy. In task 1, the imitation level of creative model is reflected in the process of imitating graphs and number patterns to make them similar to existing graphs and number patterns. In task 2, the imitation level of creative model is reflected in the process of copying only the available data. This shows that the subject's imitation level of creative model in task 1 and task 2 is consistent. Students' activities on the imitation level of creative model are shown in Table 4.

In task 1, subjects only imitated the form of graphs and trends in the sale of "teh botol" so that the two soft drinks have similarities in both graphical form and increase in sales results which experience an equal increase every year. As the results of the interview between Researcher (R) and student (S) as follows: 


\section{R: How did you complete task 1 ?}

S: I saw the difference in the increase of "Teh Botol" was six, then I followed that until 2009 it increased to six until obtaining 64. In addition, in graph of "Teh Kotak", the scores must be the same in 2009, and therefore I started to make it from the back first from year 2009. From score 64, I reduced 4 each year until 2000 the sales result was 28 .

R: Why did you choose 4, not other numbers?

S: Because it's free to choose, Ma'am.

R: Why did not have 6 so it is the same as "Teh Botol"?

S: So the graphics didn't coincide, Ma'am.

Table 4

Students' activities on the imitation level of statistical creative models

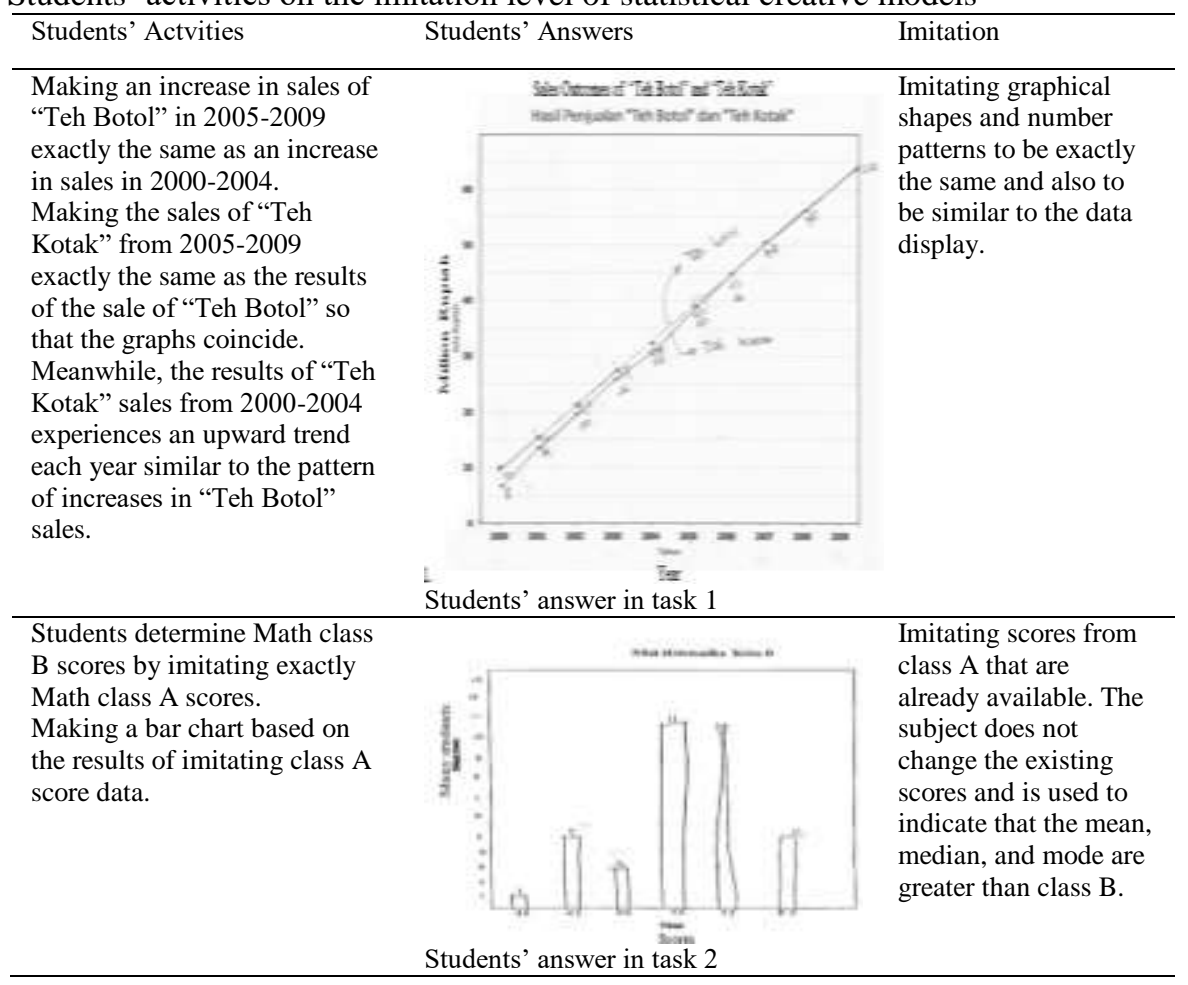

The subject who are at the imitation level in determining the results of the sale of "Teh Botol" in 2005-2009 imitated exactly the same increase in sales results in 2000-2004, amounting to IDR 6 million each year. The subject used IDR 6 millions to continue the pattern of increase in sales of "Teh Botol" in 2005-2009 so that the results of the sale of 
"Teh Botol" in 2009 were IDR 64 Millions. Then, the subject made a chart of the sales of "Teh Kotak" starting in 2009 and imitating the pattern of increase in sales of "Teh Botol" which has the same increase every year. The subject made an increase in the sales of "Teh Kotak" by IDR 4 millions annually. From the 2009 sales of IDR 64 millions, the subject made a downward trend by counting down IDR 4 millions annually so that the results of "Teh Kotak" sale in 2000 were IDR 28 millions. In this case, the subject made a pattern of the sale of "Teh Botol" in the form of arithmetic with a difference of IDR 6 millions. By using the concept of the arithmetic sequence, the subject imitated it to determine the results of "Teh Kotak" sales with a difference of IDR 4 millions. The imitation level of creative models carried out by the subject in task 1 is reflected in the process of imitating graphs and number patterns.

In task 2, the imitation level of creative models is reflected in the subject's activities in determining Mathematics class B score which imitates exactly Math class A score. Although in task 2, it is stated that the subject is free to determine the range of Math class B scores (scores 0-100), but the subject chose to emulate all class A Math scores. To make a bar chart, the subject made the horizontal axis exactly the same as Math class A scores. In other words, the subject used all class A scores, i.e. scores of 40, 45, 60, 70, and 85 to make a bar chart of Mathematics class A score. Next, the subject made the frequency on the vertical axis so that the mean, median and mode of class B is greater than class A. The position of the subject at the imitation level is strengthened by the results of the following interview.

R: Why did you choose scores on the horizontal axis like that? (Pointing to the bar chart)

S: The score I made is the same as class A, Ma'am.

$R$ : What was your reason of making the same score and not choosing another score?

\section{S: I just made it the same.}

The subject admitted that even though he had read the problem which stated that he was free to choose class B scores from 0-100, the subject still made class B scores the same as class A scores. This shows that the subject only imitated exactly the same scores as there were to complete descriptive statistics problem. The subject could determine the mean of class A of 65 , the median and mode of 60 . Thus, the subject determined the score of 70 has the greatest frequency of 11 students so that the mode and median of class B is greater than class A. The subject designated 26 students scored more than 70 and there were 9 students scored less than 70 , so the subject was convinced that the mean of class B was greater than grade A.

In carrying out descriptive statistical activities on task 1 and task 2 , the subject depended only on the information displayed in the assignment. This is in line with the opinion of Mecca \& Mumford (2013) who state that imitations occur if there are objects to be emulated or imitated so imitations depend on the way people work by example. For example, in task 1, students created ad positive trend in the sales of "Teh Kotak" because there are examples of graphs in the form of a positive trend in the sales of "Teh 
Botol" displayed in task 1. Likewise in task 2, students made Math scores in class B because students observed that class A contains Mathematics scores. Mathematics scores in class A can also be used for students in class B. In this case, students can get information about something they are experiencing directly and from what is around them. Zmyj et al. (2010) state that children are more likely to imitate a reliable model than an unreliable one. Meanwhile, Okada \& Ishibashi (2016) state that imitation is the core of the learning process, one imitates the attitudes of others not only on its surface but also at a deep cognitive process level.

\section{The Modification Level of Statistical Creative Model}

The modification level of creative model occurs when the subject modifies and combines components/data/strategies in completing the task. In task 1, the subject modified some or all of the graphic shapes and numbers patterns that exist to construct the graph. This is consistent with the completion of task 2, where the subject modified student class A scores data and then data were used to construct class B data completion. Some examples of the modification level creative models are presented in table 5 below.

In the modification level of creative model, the subject modified the pattern of increase in sales of "Teh Kotak" sales so that it is not the same as "Teh Botol" and therefore the graph form is different from "Teh Botol" graph. The position of the subject at the modification level is supported by the results of interviews conducted by the researcher with a student as follows:

\section{R: How did you complete task 1?}

S: In making “Teh Botol” graph from 2005-2009, Ma'am. I followed 6 multiples like that in 2000-2004.

$R$ : Why not having another multiple?

S: I thought the increase from 2000-2004 was steady so I also made steady increases for 2005-2009.

R: Why not making it go up and down like "Teh Kotak" graph?

S: I just continued the previous one, Ma'am.

R: Why do the lines on "Teh Kotak" graph go up and down?

S: Because I made it different from "Teh Botol”, Ma'am. 
Table 5

The students' activities on the modification level of statistical creative models

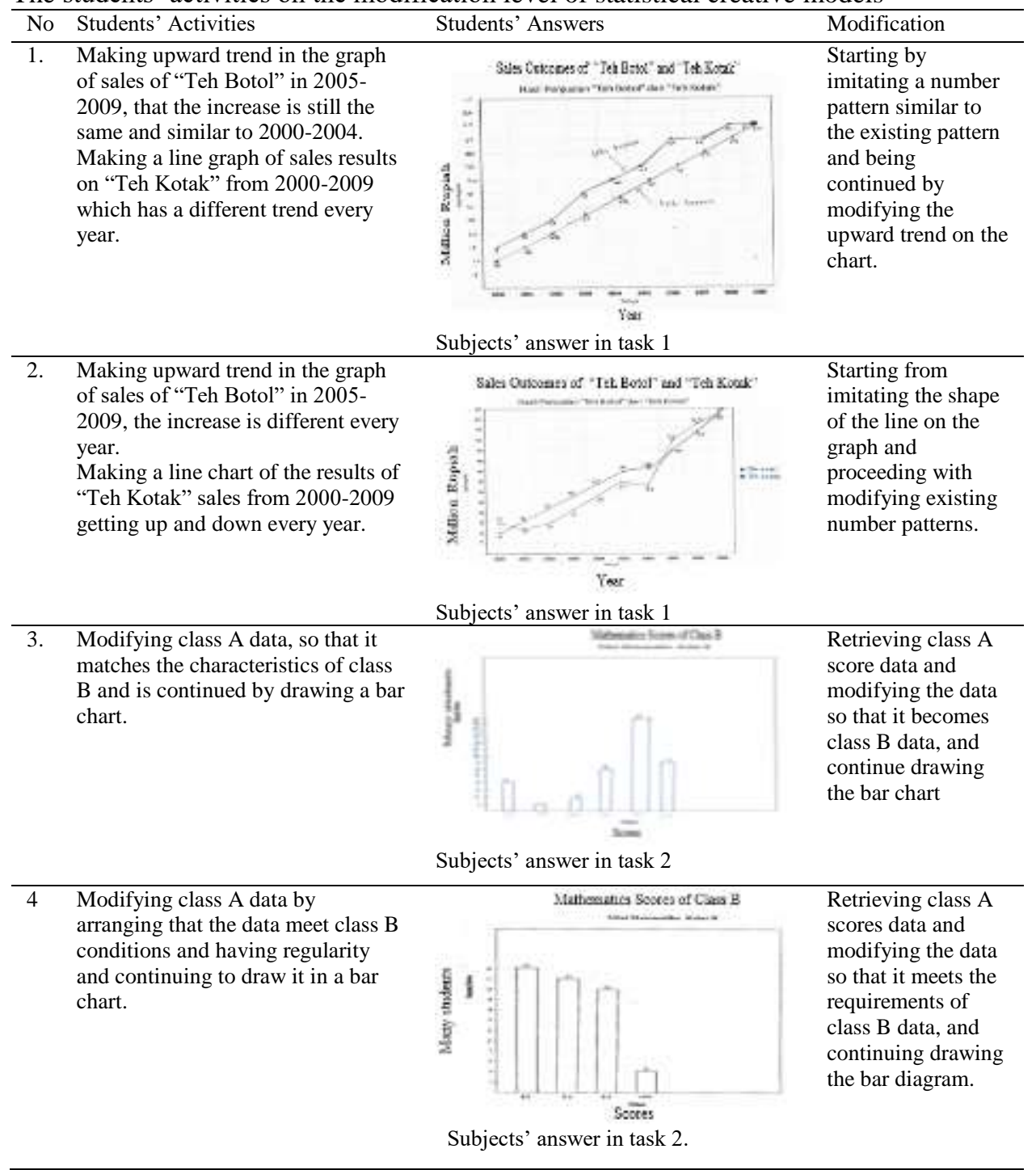

In task 1, the subject made a line on the sale of "Teh Botol" from 2005-2009 by continuing the previous year's line. From 2000-2004, the results of the sale of "Teh Botol" increased by IDR 6 millions each year, so the student added IDR 6 millions to the results of last year's sales. In this case, the subject made modifications by changing the trend in the sales of "Teh Botol" so that the sales of "Teh Kotak" experienced an up 
and down trend. The student made different results from the sale of "Teh Kotak" and "Teh Botol", so that the shape of the trend line on the two soft drinks charts was also different.

In task 2, the subject used some of Mathematics Class A scores, namely scores 45, 60 and 70 and modified them into 50, 65, and 90. These scores were used on the horizontal axis in the bar diagram of Mathematics class B scores. Meanwhile, on the vertical axis, the subject determined the number of students so that the mean, median, and mode of class B were greater than class A. The subject also used grade 85 in class A and modified other scores to be 90,95 , and 100 . These scores were used by the subject to create a class B bar chart. The position of the subject at this modification level is supported by the results of the interview as follows:

Q: Why did you make a bar chart like this (pointing to students' answers)?

S: Because looking at the problem, Ma'am. From the questions, it was obtained in class A that there were 30 students, from a variety of scores from 40 to 85 . The instruction mentions to make a class $B$ bar chart with any numbers scoring from 0 to 100 . The scores of mean, median, and mode of class B must be greater than class $A$. The first was to be recorded first in class $A$. In class $A$, it was obtained a mean of 65, a mode of 60, and a median of 60. The way I found this class $B$ scores was by first choosing the high numbers so that the mean, median, and mode of class $B$ were greater than class $A$.

P: Why were scores 85, 90, 95 and 100 selected for class B scores? Why not other scores?

S: I chose the biggest score in class A, which is 85 , then I chose a bigger number than 85 so that the mean, median, and mode are bigger than class $A$.

From the interview, it appears that the subject modified the data by combining the highest score in class $\mathrm{A}$, which is 85 with other scores greater than 85 . This was done by the subject to ensure the mean, median, and mode scores of class B were greater than class A, even without mathematical calculations.

The modification level of creative models was done by modifying data through merging and synthesizing several objects or concepts to produce new objects or concepts. This is in line with Reading \& Canada (2011) which says that through synthesis such as combining the concept of central tendency with the concept of measures of dispersion, a new concept emerges, namely data distribution as a fundamental concept.

\section{The Construction level of Statistical Creative Models}

Construction level of creative models is an activity carried out by someone in developing new information. The Construction level in solving descriptive statistical problems is marked by the subject developing existing line graphs into new line graphs to solve data presentation problems in graphical form. The subject creates a new bar chart based on a table to solve the problem of central tendency measures. The activities of the subjects in task 1 and task 2 in the construction level of creative models are presented in Table 6. 
To further explore the position of the subject at the construction level, the researcher conducted interviews with the subject as follows.

R: How did you complete task 1 ?

S: I made a graph of "Teh Kotak" and "Teh Botol" from 2005-2009, some went up and some went down, Ma'am. It was because I thought that every sale does not always increase or decrease continuously, there are times when the sales have increased and decreased too, so I made the graph go up and some go down.

$R$ : What was the initial step?

S: First, I made the sale of "Teh Botol" from 2005 to 2009 up and down, Ma'am. Then I made the sales of "Teh Kotak" starting in 2000, the score was 17, then in 2001 it decreased to 10, and in 2002 it increased again to 26, in 2003 it increased again to 23, in 2004 to 43. But in 2005 it experienced decreased to 25, in 2006 it rose again slowly to 29, in 2007 it rose to 35, in 2008 it rose to 40 and finally in 2009 the sales of "Teh Kotak" and 'Teh Botol" were equal to 50. Therefore, in the middle of the year, the sales had decreased drastically.

$R$ : Are there any number patterns that you made in determining them?

S: No ma'am, I just took it randomly.

$R$ : What are the reasons for taking it randomly?

S: There was no specific reason, Ma'am. I just created it myself. 
Table 6

The students' activities on the construction level of statistical creative models

\begin{tabular}{|c|c|c|}
\hline Students' Activities & Students’ Answers & Construction \\
\hline $\begin{array}{l}\text { Making a line on the graph of the } \\
\text { results of "Teh Botol" sales from } \\
2005-2009 \text { going up and down. } \\
\text { Making a line graph of the results of } \\
\text { "Teh Kotak" sales from } 2000-2009 \\
\text { going up and down every year. }\end{array}$ & Subjects' answer in task 1 & $\begin{array}{l}\text { Constructing } 2 \\
\text { different new } \\
\text { patterns. }\end{array}$ \\
\hline $\begin{array}{l}\text { Making a line on the graph of the } \\
\text { results of "Teh Botol" sales from } \\
\text { 2005-2009 going up and down } \\
\text { Making a graph of the results of } \\
\text { "Teh Kotak" sales from 2000-2004 } \\
\text { exactly the same as "Teh Botol". } \\
\text { Meanwhile, the trend line of } 2005 \text { - } \\
\text { 2009 sales results going up and } \\
\text { down. }\end{array}$ & Subjects' answer in task 1 & $\begin{array}{l}\text { Developing new } \\
\text { patterns based on the } \\
\text { given graph. }\end{array}$ \\
\hline $\begin{array}{l}\text { Making a bar diagram of Math class } \\
\mathrm{B} \text { in which all scores of students in } \\
\text { the class are different from class } \mathrm{A} \text {. }\end{array}$ & $\begin{array}{l}f_{1} \\
\text { Subjects' answer in task } 2\end{array}$ & $\begin{array}{l}\text { Constructing new } \\
\text { Mathematics scores. }\end{array}$ \\
\hline $\begin{array}{l}\text { Making a bar diagram of Math class } \\
\text { B scores in which all students in } \\
\text { class B have the same scores, the } \\
\text { numbers are different are different } \\
\text { from students class A scores. }\end{array}$ & $\frac{1}{3}$ & $\begin{array}{l}\text { Designing new forms } \\
\text { from bar charts to } \\
\text { make them more } \\
\text { efficient. }\end{array}$ \\
\hline
\end{tabular}

In completing task 1 , the subject of the construction level of creative models was not affected by the shape of the pattern or the shape of the trend in the graph in the problem. The subject created his own pattern and shape of the trend on the graph. The subject believed that the sales results do not have to increase continuously, sometimes they also increase and decrease. In this case, the subject is able to connect the problem of the questions with the problem in the real life. The subject was not fixated on what is displayed in the problem, but students thought realistically and logically to complete the tasks associated with everyday life. The pattern of numbers created by the subject was irregular, meaning that the amount of increase in sales does not form a line that has a regular pattern so that the form of the graph is different from the graph displayed in the task.

In task 2, the construction level subjects created a bar chart of Math class B scores by designing their own Mathematics scores so that they are not similar to or equal to Math 
class A scores. In task 2, subjects can use the scores in the range 0-100, the range of scores used by the subjects to make a new score for class B. The activity carried out by the subjects in the construction level of creative models is to design a new grade so that the Math scores of students in class B are different from the scores of students in class A. The student chose Class B students scores of 30, 35, 50, 65, 90, 95 and 100 where all the scores are different from the scores of students in class A. These scores were used by the subjects to make a bar chart, where the horizontal axis contains students scores and the vertical axis contains the number of students who received these scores. Subjects determined that more students scored 90, 95 and 100, i.e. there were 27 students and 8 students scored lower than 90 . The creative process of the construction level subjects was reflected in the results of the following interview.

\section{R: How did you answer task 2? (Pointing to student's answer paper)}

S: Firstly, I set the mean, median, and mode of class A. The mean of class A was 65, the median and mode were 60. In order to be bigger than class A, I made high scores in class B. There were scores of 90,95, and 100. I made the bar high. Class B was 95 because there were 10 people, while in class A there was a low grade and a high grade, but the score was not up to 100. Because in the problem class B had to be larger on the mean, median, and mode, so I made only few who got low scores and many who got high scores.

R: Why did you choose these scores for class B? (pointing to the horizontal axis of the bar chart)

S: Because in a class there are usually those who get low grades, there are also those who are medium, there are also those who are high, and very high. I made it different so class A scores are different from class $B$.

The subject determined the scores of mean, median, and mode of class A first before choosing the Mathematics score of class B so that the mean, median, and mode of class $\mathrm{B}$ are greater than class A. From the calculation results, the scores of mean, median, and modus of class A are 65, 60, and 60. The subject could ensure the scores of mean, median, and modus of class B were greater than class A without doing mathematical calculations by placing the number of students getting higher than 65 . Activities carried out by the subject are classified as construction level. This is in accordance with the opinion of Sheffield (2018) that students' solutions are considered creative if the student can produce something unique and new to what is in their environment.

Furthermore, to find out whether or not there are differences in the creative models of male and female subjects performed in completing descriptive statistical tasks, Chi

Square non-parametric statistical test was performed. Chi-square test results obtained $p$ $=0.971>0.05$. This shows that there is no significant difference in imitation, modification, and construction level of creative models between male and female subjects. Therefore, it can be concluded that there is no relationship between creative models with the sex of students in completing descriptive statistical activities. The 
results of this research are in line with research conducted by Naderi et al. (2009) who found that there were no differences in perceptions of creativity between male and female students. Unlike the case with research conducted by Baran, Erdogan, \& Cakmak (2011) which found a relationship of creativity with student gender.

\section{DISCUSSION}

Mathematical problems that can foster students' mathematical creative thinking are usually open so that they can give students freedom to express new ideas. Students must be involved in activities that give them space to explore problems, and ideas needed to solve problems (Nadjafikhah, Yaftian, \& Bakhshalizadeh, 2012; Svecova, Rumanova, \& Palovicova, 2014). Problems that can foster creative thinking are usually in the form of multiple solutions (Sriraman, 2009).

There are three ways in which the subject is done to solve the descriptive statistics task: (1) the subject imitate the graphs or bar charts presented on the problem, (2) the subject modifies the trend of the lines in the existing graph or modifies the data in the task, (3) the subject construct to new graph or create new values from available data. This is in accordance with Mueller et al. (2018), explain that numerical ability can significantly predict decision making accurately. This is also confirmed by Cooper (2018) where students use sense in comparing the variability of several groups of data on a bar chart, histogram and the value of a bar chart. The three ways in which students solve descriptive statistical problems to show the creative models of imitation, modification and construction levels

In this research, it was also found that there was no relationship between students' gender and the level of the students' creative model. That is, differences in the level of the creative models of students are not influenced by male or female. Thus, it can be concluded that the creative models of the imitation, modification, and creation levels of descriptive statistical activities has nothing to do with gender. The same research on gender differences has also been done by Baer \& Kaufman (2008) who found that there were no significant differences between gender and student creativity. However, there are also studies that have proven that male students are superior to female students in creativity using the Consensual Assessment Technique (Tsai, 2013).

\section{CONCLUSIONS}

The creative models of students in descriptive statistical activities in this research consist of three levels, namely imitation, modification, and construction. The imitation level of creative model is shown in the form of students' creativity in imitating objects that exist in the problem both in the form of numbers and graphical forms, as well as imitating the solution strategies that have been carried out. The modification level of creative model is shown in the form of modifying some or all of the existing objects and then adding other different objects to produce new objects. Meanwhile, construction level appears when students find new ideas or inspiration that are different from existing objects. Of the three level of creative models, there was no significant difference in the creative models of male and female students in solving descriptive statistical problems. This research has implications for Mathematics teachers to be able to design problems 
that demand the emergence of creative model in students. Creativity can emerge from within the students themselves. The teacher is expected to be able to direct students' creativity so that students freely determine various forms of answers without having to be fixated on only one correct answer.Testing inferential statistics in this research is limited to testing differences in students' creative model based on gender. Further research needs to be discussed about the factors that affect students' creative models, such as self-beliefs, student attitudes in Mathematics and mathematical achievement of students.

\section{REFERENCES}

Aoyama, K. (2007). Investigating a Hierarchy of Students' Interpretations of Graphs. International Electronic Journal of Mathematics Education, 2(3), 298-318.

Baer, J., \& Kaufman, J. C. (2008). Gender Differences in Creativity. Journal of Creative Behavior, 42(2), 75-104.

Baran, G., Erdogan, S., \& Cakmak, A. (2011). A Study on the Relationship between Six-Year-Old Children's Creativity and Mathematical Ability. International Education Studies, 4(1): 105-111

Beghetto, R. A. (2017). Lesson unplanning : toward transforming routine tasks into nonroutine problems. ZDM Mathematics Education, 49(7), 987-993. https://doi.org/10.1007/s11858-017-0885-1

Brunkalla. (2009). How to Increase Mathematical Creativity-An Experiment. The Montana Mathematics Enthusiast, 6 (1\&2): 257-266

Chamberlin, S.A. \& Moon, S.M. (2005). Model-Eliciting Activities as a Tool to Develop an Identify Creatively Gifted Mathematicians. JSGE: The Journal of Secondary Gifted Education, 17 (1): 37-47.

Cooper, L. , \& Shore, F. S. (2010). The Effects of Data and Graph Type on Concepts and Visualizations of Variability The Effects of Data and Graph Type on Concepts and Visualizations of Variability. Journal of Statistics Education, 18(2). https://doi.org/10.1080/10691898.2010.11889487

Cooper, L. (2018). Assessing Students ' Understanding of Variability in Graphical Representations that Share the Common Attribute of Bars. Journal of Statistics Education, 26(2), 110-124. https://doi.org/10.1080/10691898.2018.1473060

Coxbill, E., Chamberlin, S.A. \& Weatherford, J. (2013). Using Model-Eliciting Activities As a Tool to Identify and Develop Mathematically Creative Students. Journal for the Education of the Gift, 36 (2): 176-197

Creswell, J. W. (2012). Educational research: Planning, conducting, and evaluating quantitative and qualitative research. Educational Research (Vol. 4). https://doi.org/10.1017/CBO9781107415324.004 
Kattou, M., \& Kontoyianni, K. (2012). Connecting mathematical creativity to mathematical ability. ZDM Mathematics Education, 45(2), 167-181. https://doi.org/10.1007/s11858-012-0467-1

Lambert, P. A. (2017). Understanding Creativity. In M. L. B. Jill B. Cummings (Ed.), Creative Dimensions of Teaching and Learning in the 21st Century (pp. 1-21). The Netherlands: Sense Publishers.

Lin, C. \& Cho, S. (2011). Predicting Creative Problem-Solving in Math from A Dynamic System Model of Creative Problem-Solving Ability. Creativity Research Journal, 23 (3): 225-261

Mann S. Prem. (2013). Introductory Statistics,Edisi 8. United States of America: John Wiley \& Sons, Inc.

Mecca.J. \& Mumford, M. D. (2013). Imitation and Creativity: Beneficial Effects of Propulsion Strategies and Specificity, The Journal of Creative Behavior 48(3), 209236. https://doi.org/10.1002/jocb.49

Mueller, S. M., Schiebener, J., Delazer, M., Brand, M., \& Brand, M. (2018). Risk approximation in decision making: approximative numeric abilities predict advantageous decisions under objective risk. Cognitive Processing 19, 297-315. https://doi.org/10.1007/s10339-018-0854-9

Naderi, H., Abdullah, R., Tengku Aizan, H., Sharir, J., \& Mallan, V. (2009). Gender Differences in Creative Perceptions of Undergraduate Students.pdf. Journal of Applied Sciences, 9(1), 167-172.

Nadjafikhah, M., Yaftian, N., \& Bakhshalizadeh, S. (2012). Mathematical Creativitty: Some Definition and Caracteristics. Procedia-Social and Behavioral Sciences, 31: 285291

NCTM.( 2000). Principles and Standard for School Mathematics. Reston, VA: The National Council of Teachers of Mathematics, Inc.

NCTM.( 2007). Principles and Standard for School Mathematics. Reston, VA: The National Council of Teachers of Mathematics, Inc.

Okada, T., \& Ishibashi, K. (2016). Imitation, Inspiration, and Creation: Cognitive Process of Creative Drawing by Copying Others' Artworks. Cognitive Science, 41(7), 1804-1837. doi:10.1111/cogs.12442

Reading, C., \& Canada, D. (2011). Teachers 'Knowledge of Distribution. In Carmen Batanero - Gail Burrill - Chris Reading (Ed.), Teaching Statistics in School Mathematics Challenges for Teaching and Teacher Education:A Joint ICMI/IASE Study (pp. 223-234). Springer Science+Business Media, LLC. https://doi.org/10.1007/978-94-007-1131-0

Sharma, S. V. (2006). High school students interpreting tables and graphs: implications for research. International Journal of Science and Mathematics Education, 4, 241-268. 
Sharma, Y. (2014). The Effects of Strategy and Mathematics Anxiety on Mathematical Creativity of School Students. Mathematics Education, 9 (1): 25-27

Sheffield, L.J. (2009). Developing Mathematical Creativity-Questions May Be the Answer. In R. Leikin, A. Berman, \& B. Koichu (Eds.), Creativity in Mathematics and the Education of Gifted Students (pp. 87-100). Rotterdam: Sense Publishers.

Sheffield, L. J. (2013). Creativity and school mathematics: Some modest observations. ZDM - International Journal on Mathematics Education, 45(2), 325-332. https://doi.org/10.1007/s11858-013-0484-8

Sheffield, L. J. (2018). Commentary paper: A reflection on mathematical creativity and giftedness. In M. F.Singer (Ed.),Mathematical creativity and mathematical giftedness. Enhancing creative capacities in mathematically promising students (pp. 405-423). Nk: Springer

Sriraman, B. (2009). The characteristics of mathematical creativity. ZDM International Journal on Mathematics Education, 41(1), 13-27. https://doi.org/10.1007/s11858-008-0114-z

Sriraman, B., Haavold, P. \& Lee, K. (2013). Mathematical Creativity and Giftedness: A Commentary on and Review of Theory, New Operational Views, and Ways Forward. ZDM Mathematics Education, 45: 215-225

Sriraman, B., \& Hadamard, Á. J. (2009). The characteristics of mathematical creativity. ZDM - International Journal on Mathematics Education, 41(1), 13-27. https://doi.org/10.1007/s11858-008-0114-z

Svecova, V., Rumanova, L. \& Pavlovicova,G. (2014). Support of Pupil's Creative Thinking in Mathematical Education. Procedia-Social and Behavioral Sciences, 116, 1715-1719.

Tabach, M., \& Friedlander, A. (2013). School mathematics and creativity at the elementary and middle-grade levels: How are they related? ZDM - International Journal on Mathematics Education, 45(2), 227-238. https://doi.org/10.1007/s11858-012-0471-5

Tsai, K. C. (2013). Examining gender differences in creativity. The International Journal of Social Sciences, 12(1), 115-122.

Voica, C. \& Singer, F.M. (2012). Creative Contexts as Ways to Strengthen Mathematics Learning. Procedia-Social and Behavioral Sciences, 33: 538-542

Yaftian, N. (2015). The Outlook of the Mathematicians' Creative Processes. Procedia Social and Behavioral Sciences, 191, 2519-2525. https://doi.org/10.1016/ j.sbspro. 2015.04.617

Zmyj, N., Buttelmann, D., Carpenter, M., \& Daum, M. M. (2010). Journal of Experimental Child The reliability of a model influences 14-month-olds ' imitation. Journal of Experimental Child Psychology, 106(4), 208-220. https://doi.org/10.1016/j.jecp.2010.03.002 